\title{
EQUILÍBRIO, ESTRATÉGIA COMPETITIVA E INOVAÇÃO: UM ESTUDO DESCRITIVO DE CASOS
}

\author{
Cícero Eduardo Walter ${ }^{1}$ \\ Rafael Leite ${ }^{2}$ \\ Liliana Craveiro ${ }^{3}$
}

\begin{abstract}
Resumo: Uma forma altamente simplista de explicar o funcionamento das organizações no mercado é dizer que estas oferecem produtos elou serviços de acordo com as necessidades do mercado de forma lucrativa. Mas, do ponto de vista estratégico, fornecer apenas aquilo que o mercado necessita, mesmo que seja melhor do que as organizações concorrentes num dado momento, pode configurar-se como uma vantagem competitiva sustentável? Após as análises da indústria automobilística e do caso da Nokia, ficou claro que o equilíbrio com as forças de mercado oferecendo o que o mercado precisa de forma lucrativa, geralmente leva as organizações a um estado de acomodação, no qual as mesmas estratégias, que no passado deram certo, continuam a ser escolhidas como a principal ferramenta de ação contra a dinâmica e incerteza dos seus ambientes, na esperança de que o que deu certo no passado continuará a sê-lo no presente e no futuro. Não basta fornecer apenas aquilo que o mercado necessita, mesmo que seja melhor do que as organizações concorrentes num dado momento. A chave para a vantagem competitiva está na inovação contínua aliada à inovação descontínua.
\end{abstract}

Palavras-chave: Ambiente Empresarial, Estratégia, Organizações, Vantagem competitiva, Inovação.

\footnotetext{
${ }^{1}$ Professor de Administração de Empresas do Eixo Gestão e Negócios do Instituto Federal de Educação, Ciência e Tecnologia do Piauí, campus Oeiras.. E-mail para contato: eduardowalter@ifpi.edu.br

2 Professor de Administração de Empresas do Eixo Gestão e Negócios do Instituto Federal de Educação, Ciência e Tecnologia do Piauí, campus Floriano.. E-mail para contato: rafaelangelo@ifpi.edu.br

${ }^{3}$ Gestora no Departamento de Compras da Plural - Cooperativa Farmacêutica.. E-mail para contacto: crcliliana@ gmail.com
} 
Title: EQUILIBRIUM, COMPETITIVE STRATEGY AND INNOVATION: A DESCRIPTIVE CASE STUDY

\begin{abstract}
A highly simplistic way of explaining the operation of organizations in the market is to say that those offer products and/or services according to the market needs in a profitably way. But from a strategic point of view, provide just what the market needs, even if it is better than competing organizations at any given time, it can be a sustainable competitive advantage? After analysis of the automotive industry and Nokia's case, it was clear that balance with market forces offering what the market needs in a profitably way, often leads organizations to a bed state in which the same strategies that in the past have worked, continue to be chosen as the main tool of action against the dynamics and uncertainty of their environment, in the hope that what worked in the past will continue to be so in the present and in the future. It is not enough to provide just what the market needs, even if it is better than the competing organizations at a given time. The key to competitive advantage lies in continuous innovation coupled with discontinuous innovation..
\end{abstract}

Keywords: Business Environment. Strategy. Organizations, Competitive advantage, Innovation.

\title{
INTRODUÇÃO
}

O funcionamento das organizações baseia-se na oferta de produtos e/ou serviços consoante as necessidades do mercado. Utilizando a conceção de Roethlisberger e Dickson, de 1971, citados por Chiavenato (2003), as organizações funcionam por meio do atendimento de uma função económica e outra social ${ }^{4}$. Algo bem simples, se comparado à miríade de processos envolvidos nesta relação de troca. Mas, do ponto de vista estratégico, fornecer apenas aquilo que o mercado necessita, mesmo que seja melhor do que as organizações concorrentes num dado momento, pode configurar-se como uma vantagem competitiva sustentável? De acordo com Martín e López (2007), uma vantagem competitiva faz referência a uma "situação de superioridade ou condições favoráveis que uma coisa tem sobre outra" (p.267), ou seja, "o conceito de vantagem competitiva entende-se como qualquer característica da empresa que a diferencia das demais, colocando-a numa posição relativa de superioridade para competir" (p.267). Na conceção da Teoria

\footnotetext{
${ }^{4}$ No que diz respeito à função económica das organizações, os autores mencionados caracterizam-na como a produção de bens e/ou serviços que promovem o equilíbrio com as forças externas, quais sejam, as forças de mercado, enquanto a função social diz respeito à promoção da satisfação social dos seus participantes.
} 
Sistémica da Administração, as empresas evitam continuamente a entropia, princípio segundo o qual, tudo tende invariavelmente à morte $\mathrm{e}$ à desorganização, por meio do equilíbrio dinâmico com as forças de mercado, o que poderíamos analogamente denominar de homeostasia e/ou adaptabilidade (adaptação que os seres vivos fazem em relação ao meio em que vivem a fim de que continuem vivos), adotando um ponto de vista biológico.

Sabendo da importância atribuída às estratégias adotadas pelas organizações para fazer frente aos desafios impostos pelos seus ambientes de negócios, decidimos por meio deste estudo de casos explorar e descrever como o equilíbrio com as forças de mercado pode levar as organizações a desvantagens competitivas a longo prazo.

O objetivo do presente estudo é suscitar uma discussão a respeito da moderna estratégia competitiva de negócios e quais as possíveis implicações da mesma para as empresas, tendo como plano de fundo a seguinte afirmação: para uma organização que atua num ambiente altamente dinâmico, estar em equilíbrio com as forças de mercado pode configurar-se como uma desvantagem competitiva. Na tentativa de obter mais informações que possam servir de base para a discussão em foco, analisaremos duas indústrias centenárias, pois são tecnicamente consolidadas: a indústria automobilística e uma empresa expoente da indústria de tecnologia - a Nokia.

$\mathrm{O}$ artigo está estruturado em cinco secções, além da introdução. $\mathrm{Na}$ segunda secção serão apresentados alguns conceitos que norteiam as estratégias de negócios, o ambiente empresarial e a inovação. Em seguida são apresentados os procedimentos metodológicos usados e os casos práticos, e por fim, são apresentados os resultados e conclusões obtidos através da análise do estudo de casos.

\section{REFERENCIAL TEÓRICO}

\subsection{Ambiente empresarial, estratégia e vantagem competitiva}

As organizações não existem no vácuo, estão imersas num cenário composto por outras organizações, que ao todo compõem a sociedade. Estão dentro de um ambiente, que de acordo com Chiavenato (2003, pg. 302), "é tudo que envolve externamente uma organização", corroborado por Oliveira (2012, pg. 79), ao afirmar que ambiente empresarial "é o conjunto de todos os fatores externos e não controláveis que, dentro de um limite específico, se possa conceber como tendo ou recebendo alguma influência da referida empresa". 
A organização depende de outras organizações para seguir o seu caminho e atingir os seus objetivos. Nenhuma organização é autónoma ou auto-suficiente. Todas as organizações dependem de outras organizações e da sociedade para poder sobreviver. Existe uma interdependência das organizações com a sociedade em geral em função das complexas interações entre elas. E algumas das consequências dessa interdependência são: mudanças frequentes nos objetivos organizacionais à medida que ocorrem mudanças no ambiente externo e um certo controlo ambiental sobre a organização, o que limita a sua liberdade de agir (Chiavenato, 2003).

Para lidar com os seus ambientes e alcançar os seus objetivos, cada organização desenvolve estratégias, pois, de acordo com Oliveira (2012, pg. 12), "o intenso aumento do nível de concorrência entre as empresas, provocado, principalmente pela globalização, pela forte evolução tecnológica e pelo maior nível de exigência dos clientes tem levado à intensificação e à maior qualidade no uso de estratégias pelas empresas".

Os modernos modelos de gestão exigem, em elevada intensidade, o delineamento e operacionalização de fortes estratégias que consolidem vantagens competitivas reais, sustentadas e duradouras para as empresas (Oliveira, 2012, pg. 12).

Neste contexto, é cada vez mais necessário que os empresários e os altos diretores das empresas dediquem um maior esforço e análise à elaboração e escolha da estratégia mais adequada para responder aos desafios do ambiente e tornar assim a empresa mais competitiva nesse contexto. Poderia afirmar-se que todas as empresas têm ou seguem uma estratégia embora, em muitas delas, permaneça implícita na mente do empresário ou da direção geral. O esforço para torna-la explícita, analisála e racionalizá-la pode ser muito valioso para melhorar a posição competitiva da empresa e, em consequência, seus resultados (Martín e López, 2007).

Uma estratégia, de acordo com Barney (2007, pg. 5), "seria uma teoria de como obter vantagens competitivas", guiada principalmente por um processo de administração estratégica definido como "um processo sequencial de análises e escolhas que podem aumentar a probabilidade de que uma empresa escolherá uma boa estratégia, isto é, uma estratégia que gere vantagens competitivas" . Já para Oliveira (2012, pg. 5) a estratégia "é o ajustamento da empresa ao seu ambiente, em geral em constante mutação, quase sempre com a empresa alterando as suas próprias características, tendo em vista esse ajustamento."

Ainda de acordo com Braney (2007, pg. 10), uma empresa possui vantagem competitiva quando "é capaz de gerar maior valor económico 
do que as empresas rivais", enquanto que para Oliveira (2012, pg.82), "vantagem competitiva é aquele algo mais que identifica os produtos e serviços, bem como os mercados para os quais a empresa está, efetivamente, capacitada a atuar de maneira diferenciada, em relação aos seus concorrentes".

\subsection{Estratégias deliberadas e estratégias competitivas}

Uma estratégia deliberada é aquela que, segundo Martín e López (2007), baseia-se "num processo racional e estruturado, controlado pela alta direção para elaborar uma estratégia que será posta em prática através de um plano relativamente predeterminado"(p.66). Para Whittington (2002) esta é a conceção clássica de estratégia, nas suas palavras:

É o processo racional de cálculos e análises deliberadas, com o objetivo de maximizar as vantagens de longo prazo. Se houver um esforço em reunir informações e aplicar as técnicas apropriadas, tanto o mundo exterior quanto a empresa, tornam-se previsíveis $e$ maleáveis, moldados de acordo com os planos cuidadosos da gerência executiva. Para os clássicos, dominar os ambientes interno e externo exige um bom planeamento. A estratégia é importante nessa análise racional, as decisões objetivas fazem a diferença entre o sucesso prolongado e o fracasso (p.03).

De acordo com Martín e López (2007), existem três níveis de estratégias; as estratégias de nível corporativo ou de empresa que tratam de "fixar a orientação básica da empresa em seu conjunto"(p.46), envolvem as decisões tais como entrar em novos mercados ou comprar outras empresas, enquanto que, as estratégias de nível competitivo ou de negócios determinam "como competir melhor num conjunto de atividades, negócios ou unidades estratégicas de negócio" (p.46) e por fim, as estratégias funcionais são aquelas que se concentram em "como utilizar e aplicar os recursos e habilidades dentro de cada área funcional da empresa"(p.47).

Nomeadamente, às estratégias de nível competitivo ou de negócios, as empresas determinam como vão competir num segmento específico, ou seja, na sua indústria, e uma vez que escolhem a indústria em que irão competir, devem determinar como irão competir nessa indústria, de forma a construir uma vantagem competitiva. De acordo com Martín e López (2007), uma vantagem competitiva faz referência a uma "situação de superioridade ou condições favoráveis que uma coisa tem sobre outra" (p.267), ou seja, "o conceito de vantagem competitiva entende-se como 
qualquer característica da empresa que a diferencia das demais, colocando-a numa posição relativa de superioridade para competir" (p.267). Dentro deste prisma, uma empresa pode adquirir vantagem competitiva mediante aspetos externos, como a capacidade de flexibilidade ao ajustar-se ao entorno ou pela capacidade de prognóstico, que seria identificar e antecipar-se às mudanças (Martín e López, 2007). Ou por aspetos internos, como a vantagem competitiva em custos ou pela vantagem competitiva na diferenciação de produtos. Para Martín e López (2007), uma vantagem competitiva em custos ocorre quando uma empresa tem "custos inferiores aos dos seus concorrentes para um produto ou serviço semelhante ou comparável em qualidade" (p.276277), enquanto que uma vantagem em diferenciação de produtos acontece quando uma empresa oferece um produto ou serviço que "sendo comparado com o de outra empresa, tem certos atributos que fazem com que o mesmo seja percebido como único para os clientes"(p.285).

De acordo com o "guru" da estratégia Michael Porter em 1982, citado por Martín e López (2007), uma empresa pode adotar duas estratégias competitivas genéricas baseadas nessas vantagens competitivas e que consequentemente a deixe em relativa superioridade em relação às demais empresas da indústria, denominadas como estratégia de liderança em custos e de diferenciação.

\subsection{Inovação: a pedra angular da moderna vantagem competitiva}

A inovação é o instrumento específico da atividade empresarial. É a ação que dota os recursos de uma nova capacidade para criar riqueza. A inovação cria, de facto, o recurso. Um "recurso" é uma coisa que não existe até o homem descobrir uma utilização para algo existente na natureza e desse modo a dotar de um valor económico (Drucker, 1987).

Os empresários (organizações) bem-sucedidos, seja qual for a sua motivação individual - dinheiro, poder, curiosidade ou desejo de fama e de reconhecimento - tentam criar valor e contribuir com algo. De qualquer modo, os empresários bem-sucedidos visam alto. Não se contentam com meros melhoramentos ou modificações daquilo que já existe. Tentam criar valores novos e diferentes satisfações, converter "matéria-prima" em "recursos", ou combinar recursos existentes segundo moldes novos e mais produtivos (Drucker, 1987).

Para Anthony e Christensen (2007, pg. 19), “a inovação é imprescindível para manter a saúde da empresa. Na verdade, a criação de novos produtos, serviços, processos e modelos operacionais contribuiu para o crescimento não apenas da empresa, mas também da economia nacional e global". Ainda de acordo com os autores supracitados, "a 
novação pode apontar para novas formas de fazer negócio, de ganhar dinheiro e de compreender o que os consumidores querem". ( Anthony e Christensen, 2007, pg. 20)

Já para Tidd, Bessant e Pavitt (2008, pg. 25), a inovação gradativamente está a tornar-se a fonte de vantagem competitiva das organizações, pois nas suas palavras:

Enquanto a vantagem competitiva pode advir de tamanho ou património, entre outros fatores, o cenário está a mudar gradativamente em favor daquelas organizações que conseguem mobilizar conhecimento e avanços tecnológicos e conceber a criação de novidades em suas ofertas (produtos/serviços) e nas formas como criam e lançam essas ofertas[...].[...] Ser capaz de fazer algo que ninguém mais pode, ou fazê-lo melhor do que outros, é uma vantagem significativa. (Tidd, Bessant e Pavitt, 2008, pg. 25)

\subsection{Inovação incremental e descontínua}

A inovação é uma questão de conhecimento - criar novas possibilidades por meio da combinação de diferentes conjuntos de conhecimentos. Estes podem vir na forma de conhecimento sobre o que é tecnicamente possível ou de que configuração pode responder a uma necessidade articulada ou latente. Tal conhecimento pode já existir na nossa experiência, baseado em algo que já vimos ou experimentamos antes, ou pode resultar de um processo de busca por tecnologias, mercados, ações da concorrência, etc. Também pode ser explícito na sua forma, codificado de modo que outros a ele possam aceder, discutir, transferir, etc. - ou pode existir de modo tácito: conhecido, mas sem formulação (Tidd, Bessant e Pavitt, 2008).

$\mathrm{O}$ processo de combinação desses diferentes conjuntos de conhecimentos numa inovação bem-sucedida ocorre sob condições de alta incerteza. Não sabemos exatamente como a inovação final será (e não sabemos como chegaremos a ela). A gestão da inovação compreende a nossa capacidade de transformar essas incertezas em conhecimento; mas só podemos consegui-lo por meio da mobilização de recursos no sentido de reduzir a incerteza - efetivamente uma ação de equilíbrio (Tidd, Bessant e Pavitt, 2008). Dito desta forma, quando uma inovação bemsucedida parte de algo já conhecido pela empresa, ou seja, com incerteza relativamente baixa, dizemos que se trata de uma inovação incremental, como o melhoramento de um novo produto ou processo existente na organização. Embora a inovação algumas vezes, envolva uma mudança descontínua - algo completamente novo ou uma resposta a condições 
completamente alteradas - na maioria das vezes ela ocorre de forma incremental. Os produtos raramente "são novos para o mundo", a inovação de processos é basicamente centrada na otimização (Tidd, Bessant e Pavitt, 2008). Entretanto, quando parte de algo totalmente novo dizemos que se trata de uma inovação descontínua, pois o nível de incerteza é relativamente alto. Para Tidd, Bessant e Pavitt (2008, pg. 35), "a inovação incremental, ainda que arriscada, é uma estratégia gerencial de grande potencial, porque inicia a partir de algo já conhecido". Entretanto, apenas inovar de forma incremental não é o suficiente, pois as inovações descontínuas podem ser a maior fonte de vantagem competitiva de uma organização porque reescrevem as regras do jogo competitivo ao criar algo totalmente novo e inédito.

\section{MÉTODO}

O presente estudo trata da criação de conhecimento do particular para o geral e do geral para o particular, caracterizando-se como um método tanto indutivo quanto dedutivo e com uma abordagem estritamente qualitativa que, de acordo com Silva e Menezes (2001, pg.20), é uma abordagem que considera que "há uma relação dinâmica entre o mundo real e o sujeito, isto é, um vínculo indissociável entre o mundo objetivo e a subjetividade do sujeito que não pode ser traduzido em números". Do ponto de vista dos objetivos a pesquisa foi descritiva e exploratória, que segundo Gil, 1991, citado por Silva e Menezes (2001, pg. 21) "visa descrever as características de determinada população ou fenómeno ou o estabelecimento de relações entre variáveis" e que, "visa proporcionar maior familiaridade com o problema com vistas a torná-lo explícito ou a construir hipóteses". Em relação aos procedimentos técnicos, trata-se de um estudo de casos com base em pesquisas bibliográficas, pois Segundo Silva e Menezes (2001), o estudo de caso "envolve o estudo profundo e exaustivo de um ou poucos objetos de maneira que se permita o seu amplo e detalhado conhecimento" (pg.21), ainda em relação ao estudo de caso, Yin (2005) o caracteriza como uma metodologia "particularmente apropriada para responder perguntas do tipo 'como' e 'por que' e é bem apropriada para gerar e construir teoria numa área onde há poucos dados e teoria e sobre o qual o pesquisador não tem total controlo" (pg.12).

A recolha dos dados foi feita por meio de pesquisas bibliográficas, que de acordo com Gil, 1991, citado por Silva e Menezes (2001, pg. 21) é "elaborada a partir de material já publicado constituído principalmente de livros e artigos de periódicos". 
A análise dos dados foi feita pela técnica da análise de conteúdo, que de acordo com Bardin (1977) se refere a um conjunto de instrumentos metodológicos que se aperfeiçoa constantemente e que se aplica a discursos diversificados. O estudo possui como limitações a falta de dados referentes aos desempenhos individuais dos objetos estudados, que ao mesmo tempo enseja o desenvolvimento de novos estudos levando em consideração a correlação do desenvolvimento de inovações incrementais e descontínuas com a participação de mercado.

\section{A INDÚSTRIA AUTOMOBILÍSTICA: REINO UNIDO, FRANÇA, ESTADOS UNIDOS E JAPÃO.}

\subsection{Reino Unido e França}

Quando alguém começa a desempenhar uma nova atividade lucrativa deve ter em mente que não estará sozinho. Outras pessoas surgirão com imitações dessa atividade, de forma que a margem de lucro passa a diminuir significativamente e, consequentemente, diminuindo a atratividade da mesma. Na medida em que a margem de lucro passa a diminuir ${ }^{5}$, reduzindo também a atratividade, alguns imitadores, ou até mesmo o pioneiro pode deixar de existir ${ }^{6}$, restando no mercado apenas aqueles que conseguiram atender as necessidades desse mercado da forma mais satisfatória e lucrativa possível, gerando assim um estado de acomodação ou equilíbrio com as necessidades deste mercado num dado momento. Vejamos o que dizem os dados a respeito da população de fabricantes de automóveis no Reino Unido e em França durante o período de 1885 a 1965 (Hannan, 1997, citado por Whittington, 2002).

Em 1885 quase não existiam fabricantes de automóveis no Reino Unido e França, a partir de 1895 começa-se a verificar o surgimento de poucos fabricantes em França, enquanto no Reino Unido surge um total de 20 fabricantes. De acordo com Luedemann (2003, p. 30), "essa produção era feita em pequena escala pelos 'engenheiros criadores', com o auxílio de uns poucos funcionários".

Em 1905, França tinha um total de 120 fabricantes de automóveis, enquanto o Reino Unido detinha 124 fabricantes. E em 1914, pela

\footnotetext{
${ }^{5} \mathrm{O}$ que antes da concorrência é denominado de "lucro de monopólio".

${ }^{6}$ Há muitas explicações para tal, para citar apenas algumas podemos identificar os altos custos de investimentos iniciais, a orientação do negócio para o curto prazo, focando apenas nos lucros imediatos da atividade sem considerar a evolução do segmento de negócio ao longo do tempo e, a concorrência predatória.
} 
primeira vez em quase 29 anos de atividade, a população de fabricantes de automóveis de França ultrapassa a do Reino Unido com quase 160 e 140 fabricantes respectivamente, atingindo assim, o pico mais alto na população de fabricantes de automóveis em França no período de 1885 a 1965. Em 1925 o Reino Unido volta à frente, com um maior número de fabricantes do que em 1914, totalizando 142 fabricantes, enquanto França diminuiu de 160 para 140 . De 1925 a 1935 a redução da população de fabricantes é gritante, em 10 anos a mesma diminuiu em 70\% em França e em 73,2\% no Reino Unido, passando a representar 42 fabricantes em França e 38 no Reino Unido.

A partir desse ano a tendência foi de redução no Reino Unido e de pequenas elevações da população de fabricantes em França seguidas de fortes reduções da mesma, chegando a um total, em 1965, de pouco mais de 30 fabricantes em França e menos de 20 no Reino Unido. Ressalta-se que durante a década de 1920 houve uma tendência mundial para a expansão de algumas fábricas, entre elas, as de automóveis, considerada como a Era da empresa moderna, caracterizada por fortes integrações verticais e horizontais e pelo capitalismo de gestão, a divisão entre os proprietários e a nova classe em ascensão, a dos gestores (Chandler, 1990, e Chiavenato, 2003, concordam, sobretudo, ao exemplificar as motivações do surgimento da grande empresa moderna, impulsionada pelo surgimento de um mercado de massa no mundo), que poderia explicar em parte a redução do número de fabricantes. Todavia, esta é apenas uma das explicações, outra mais contundente está contida no trabalho de Henderson (1989, apud Whittington, 2002, p. 21), que enfatiza o fato de que "a sobrevivência das empresas num ambiente competitivo depende das estratégias de diferenciação".

Seguindo a afirmação de Henderson em 1989 (citado por Whittington, 2002), vamos analisar por que a estratégia de diferenciação é a base da sobrevivência das empresas num ambiente competitivo, ainda dentro da indústria automobilística. Vejamos o caso da Ford e da General Motors nos Estados Unidos e da Toyota no Japão.

\subsection{Estados Unidos e Japão}

Sempre que o nome Ford nos vem à mente quase que automaticamente lembramo-nos da linha de produção, uma inovação de processo que alterou as bases da competição no mercado de automóveis no ano de 1908 nos Estados Unidos. Nesta época existiam cerca de 500 fabricantes de automóveis nos Estados Unidos, que produziam carros sob encomenda, que custavam cerca de duas vezes a média do rendimento familiar anual. Ford, ao analisar o estado do mercado de automóveis 
americano viu uma oportunidade, de oferecer um carro a um preço acessível, concebendo assim o seu famoso Ford Modelo T (Kim e Mauborgne, 2005), que apesar de ser apenas de uma cor (Preto), era um carro durável e fácil de reparar. A estratégia utilizada por Ford foi a redução de custos, entre 1908 e 1923, quando a produção acumulada havia alcançado cerca de 8000000 unidades, os custos de produção caíram de 3000 dólares para menos de 900 dólares, como consequência da aplicação de uma série de medidas que incluíam o desenvolvimento de um processo de produção integrado e mecanizado na cadeia de produção que reduzia o tempo de produção de 21 dias em 1908 para 4 dias em 1923; e reduzia o pessoal utilizado para as atividades de planeamento e controlo, entre outras.

A quota de mercado da Ford disparou de 9\%, em 1908, para 61\%, em 1921. Já em 1923, a maioria das famílias americanas possuía um automóvel (Kim e Mauborgne, 2005). Aqui, claramente Henry Ford conseguiu um equilíbrio com as forças de mercado, estava a oferecer exatamente o que este necessitava num dado momento de forma altamente lucrativa. Entretanto, para Martín e Lopéz (2007), "a redução de custos de fabricação na Ford conduziu a um fracasso posterior. A estratégia foi tão dominante e a organização estava tão ocupada com ela que lhe faltaram recursos e orientações necessárias para sentir a mudança do meio e reagir a ela", pois, em 1924 a General Motors (GM) lançou uma nova linha de automóveis, caracterizada por uma linha com ampla variedade de modelos, com novas cores e estilos e atualizados todos os anos, recorrendo a uma tendência de mudanças no estilo de vida e necessidades dos americanos.

De 1926 a 1950, a quantidade de carros vendidos nos Estados Unidos saltou de dois milhões para sete milhões por ano, e a General Motors aumentou sua participação no mercado total de $20 \%$ para $50 \%$, enquanto a da Ford caía de 50\% para 20\%. Seguindo o grande sucesso da GM, a Ford e a Chrysler passaram a imitar a estratégia de produção de novos modelos de carros para atender diversos estilos de vida e satisfazer diferentes necessidades, e assim iniciou-se um período de acomodação no sector (Kim e Mauborgne, 2005).

Ressalte-se que a GM utilizou uma estratégia de diferenciação para obter uma vantagem competitiva que, de acordo com Walter (2014, p. 61), "implica em fazer com que o produto ou serviço oferecido seja visto pelos consumidores como único, de forma que os mesmos fiquem propensos a pagar um preço superior à concorrência por esse fator de diferenciação", enquanto a Ford utilizou uma estratégia de liderança em 
custos, que de acordo com o autor supracitado "consiste em oferecer produtos ou serviços com uma estrutura de custos menor do que a dos concorrentes, podendo oferecer produtos ou serviços com um preço baixo" (Walter, 2014, p. 61).

Em ambos os casos, podemos dizer que as empresas conseguiram atingir o equilíbrio com as forças de mercado, pois, aperceberam-se da "janela de oportunidade" existente, que segundo Hisrich et al (2009) "é o tempo disponível para o lançamento de um negócio". Mas no caso da GM, o equilíbrio foi mais duradouro, pois, a organização estava mais apta a reagir às mudanças do mercado, corroborando a afirmação de Henderson (1989, apud Whittington, 2002) de que a diferenciação é fator primordial de sobrevivência num ambiente altamente competitivo e dinâmico. Se a estratégia de diferenciação é a melhor estratégia num ambiente competitivo, resta-nos dizer que a mesma pode ser utilizada com êxito em qualquer situação em que o mercado se apresente como dinâmico e incerto. Correto? Vejamos como as empresas que adotaram essa estratégia (GM, Ford e Chrysler) se saíram durante a crise do petróleo em 1973.

Durante a década de 1970, com a crise do petróleo, os consumidores americanos passaram a adotar outros critérios para a compra de automóveis. Com o preço do petróleo demasiado elevado, carros mais compactos, eficientes e de qualidade, eram vistos como os mais apropriados para o momento. As grandes fabricantes dos Estados Unidos (GM, Ford e Chrysler), que fabricavam carros seguindo uma lógica de "quanto maior, melhor" viram as suas vendas em declínio vertiginosamente. Os Japoneses, que saíram derrotados da Segunda Grande Guerra Mundial, no intuito de acompanhar a produtividade americana, estabeleceram as bases para um sistema de produção que pudesse dar competitividade à indústria japonesa como um todo, tendo a indústria automobilística em seu cerne, representada fortemente pela Toyota, amplamente subsidiada pelo Ministério de Comércio Exterior e Indústria. A lógica a priori do sistema de produção da Toyota era bastante simples, perceberam que para alcançar os americanos em três $\operatorname{anos}^{7}$ deveriam ser capazes de evitar todo e qualquer desperdício, identificando-os e trabalhando arduamente para eliminá-los, nascendo assim o just-in-time.

7 Toyoda Kiichiro, o presidente da Toyota no período pós-guerra teria dito: "Alcancemos os americanos em três anos (em termos de produtividade). Caso contrário, a indústria automobilística japonesa não sobreviverá." (CORRÊA e CORRÊA, 2010). 
Os carros japoneses eram superiores em qualidade e eficiência, em 1973 a indústria automobilística japonesa dominou cerca de $20 \%$ do mercado doméstico americano, o resultado foi logo sentido na sociedade americana, fábricas foram fechadas e milhares de pessoas perderam o emprego (Corrêa e Corrêa, 2010). Para se ter uma ideia do impacto do sistema de produção Toyota na indústria de automóveis americana, em 1980 a mesma teve um prejuízo agregado de 4 biliões de U\$ e a Chrysler escapou por pouco da falência, graças a uma operação de resgate do governo (Kim e Mauborgne, 2005).

Então, o que aconteceu à estratégia de diferenciação utilizada pelos fabricantes de automóveis americanos? Quando as organizações se equilibraram com as forças de mercado e quando ofereceram exatamente aquilo que o mercado precisava de forma lucrativa, entraram num estado de acomodação, passaram a utilizar sempre as mesmas estratégias, que no passado deram certo, na esperança de que resultem no presente e no futuro. Estar em equilíbrio com as forças de mercado parece-nos ser uma desvantagem a longo prazo, pois este mesmo equilíbrio tende geralmente a levar à acomodação, com impacto negativo na competitividade das organizações.

\section{NOKIA: DE LÍDER PARA TAKEOVER}

Outra indústria marcada por forte dinamismo e mutação é a de tecnologia. E, para darmos continuidade a discussão em foco passaremos a analisar como outra empresa centenária passou da empresa mais lucrativa no ramo das telecomunicações para um objeto de efetiva aquisição.

De acordo com Tidd, Bessant e Pavitt (2008), a Nokia remonta a 1865, quando iniciou as suas operações como uma empresa florestal, atuando assim por quase 100 anos até fazer, nos anos 1960, uma série de aquisições não relacionadas, transformando-se em 1990 de um vasto conglomerado com uma variedade de produtos maduros e baixa margem de lucro, no maior fabricante mundial de telemóveis, com aproximadamente $30 \%$ do mercado global de aparelhos portáteis e uma fatia de $60 \%$ dos lucros da indústria. Ainda de acordo com os autores supracitados, o sucesso da Nokia baseou-se numa combinação de inovação tecnológica e design de produto, proporcionando um crescimento anual na ordem de $40 \%$, chegando a vender no ano 2000 mais de 400 milhões de aparelhos telefónicos, além de obter margens de lucros até $25 \%$, enquanto os seus rivais alcançavam apenas de 1 a $3 \%$. 
A Nokia chegou a ser a quinta maior empresa da Europa empregando 44.000 pessoas em 11 países, permanecendo em 2004 como o fabricante de telefones móveis que mais lucrava. Mas, segundo Tidd, Bessant e Pavitt (2008, p. 267), "em 2004 a Nokia começou a perder espaço de mercado ao enfrentar o aumento da concorrência da SonyEricsson e da Samsung. Uma razão foi a demora em desenvolver modelos com flip em que os concorrentes foram pioneiros", mesmo destinando cerca de 9\% dos seus rendimentos em $P \& D$, redundando numa diminuição da margem de lucro para menos de $20 \%$, enquanto que a fatia de mercado diminuiu para menos de 30\%, e em 2013 foi adquirida por 17 biliões de \$Reais pela Microsoft. A Nokia não se diferenciava apenas das concorrentes, como também continuamente inovava, o que aconteceu de errado? Vejamos retrospetivamente.

"De vez em quando aparece um produto revolucionário que muda tudo" (Isaacson, 2011), esta frase pronunciada por Steve Jobs, Presidente executivo da Apple, no lançamento de um produto em janeiro de 2007, foi provavelmente o começo do fim para a Nokia enquanto empresa independente. Neste dia foi introduzido um produto revolucionário que teria um impacto significativo na indústria de telemóveis, que alteraria profundamente as bases da competição nesse mercado, neste dia era oficialmente lançado o iPhone, uma inovação pontuada por descontinuidade. De acordo com Tidd, Bessant e Pavitt (2008, p. 38):

Na maioria das vezes, a inovação ocorre dentro de um conjunto de regras de jogo que são claramente entendidas e que envolvem jogadores tentando inovar na busca pela melhoria daquilo que já vem fazendo (produto, processo, posição, etc.). Alguns alcançam-na mais efetivamente do que outros, mas as "regras do jogo" estão definidas e não mudam. [...] No entanto, às vezes, algo acontece que desloca esse padrão e altera as regras do jogo. (Tidd, Bessant e Pavitt, 2008, p. 38)

O iPhone é um exemplo de inovação descontínua, por avanços tecnológicos tanto em hardware quanto em software, como por exemplo, a eliminação total do teclado de hardware e inclusão de uma tela multitoque de vidro. A sua introdução alterou drasticamente as regras do jogo, estabelecendo-se como um novo padrão dominante no mercado de telecomunicação, padrão este que foi adotado com dificuldades pela Nokia, pois, estava profundamente comprometida com o modelo que fizera com que ela chegasse a ser a maior fabricante de telemóveis do mundo, o BlackBerry, totalmente contrário ao novo padrão estabelecido 
pelo iPhone, fazendo com que perdesse gradativamente Market Share e margem de lucro.

No fim de 2010, a Apple tinha vendido 90 milhões de iPhones, e abocanhou mais da metade dos lucros totais gerados no mercado mundial de telemóveis (Isaacson, 2011, p. 493), e em 2013 a Nokia foi adquirida pela Microsoft por 17 biliões de \$Reais. O que se pode extrair desta situação, é que a Nokia continuou a inovar na melhoria daquilo que já vinha a ser feito, ou seja, "fazendo melhor aquilo que já fazemos", enquanto a Apple inovou de forma descontínua, "fazendo algo totalmente novo", alterando o equilíbrio de mercado a seu favor e colocando a Nokia em sérias dificuldades. Mais uma vez, percebe-se que oferecer apenas aquilo que o mercado necessita num dado momento e apoiar-se estritamente nisso pode configurar-se como uma desvantagem competitiva a longo prazo, muitas vezes levando a desfechos trágicos como o caso da Nokia.

\section{CONCLUSÃO}

A priori parece ser contra senso, "não perseguir veementemente o equilíbrio com as forças de mercado", visto que isso é simplesmente atender às necessidades de um dado mercado de forma lucrativa, entretanto, constata-se que as organizações que fazem exatamente isso tendem a ser menos competitivas no longo prazo, muitas vezes com causas catastróficas.

Este efeito parece estar a desenhar-se no mercado de telecomunicações nos últimos anos. E quem parece estar a entrar neste circulo vicioso é a empresa Oi. A falta de investimento em inovação continuada tem levado a empresa - líder de mercado em vários serviços a perder participação de mercado constante em serviços para telemóveis, telefones fixos e banda larga. De acordo com Grisotto e Rydlewsky (2015), num artigo intitulado "Como derrubar uma empresa", publicado na Revista Época Negócios, a participação de mercado da Oi nos sectores de telemóveis, telefones fixos e banda larga encolheu 4,64\%, 23,48\% e $18,35 \%$, respetivamente, no período compreendido entre 2010 e 2014, enquanto concorrentes como a TIM e a Claro/Embratel aumentaram as suas respetivas participações de mercado em telemóveis e banda larga. A redução de $23,48 \%$ de participação de mercado da Oi no segmento de telecomunicações pode ser justificada por se tratar de uma tendência para a substituição dos telefones fixos por telemóveis, entretanto, nos 
segmentos de telemóveis e banda larga a resposta pode estar na falta de investimentos e inovação.

Ainda de acordo com os autores supracitados, nos últimos anos - 2007 a 2014 - a Oi teve endividamento multiplicado, de 3,4 bi para 47,8 bi. Isto desbastou a sua capacidade de investimento. O problema é que é possível competir num mercado de capital intensivo como o das telecomunicações sem investimentos em inovação a longo prazo. Isto reflete-se no valor de mercado das ações que dispersaram enquanto os papéis da concorrência avançaram no mesmo período - a queda foi de $92 \%$ só nos últimos dois anos. Se a Oi terá o mesmo caminho das empresas listadas aqui, só o tempo dirá. Mas o certo é que estamos a presenciar os primeiros sinais do fenómeno da falta de inovação contínua e descontínua numa grande empresa brasileira.

Como ficou claro com a análise das empresas e indústrias supracitadas, não basta apenas diferenciar-se ou dedicar margem considerável das receitas para departamentos de Pesquisa e Desenvolvimento, é necessário inovar de forma incremental, "fazendo aquilo que fazemos, mas melhor", como também de forma descontínua, "fazer algo diferente do que já fazemos", como no caso do iPhone lançado em 2007 em comparação com a Nokia. Fato este corroborado por Tidd, Bessant e Pavitt (2008, p. 30), ao afirmarem categoricamente que "sejam quais forem as condições tecnológicas, sociais ou mercadológicas envolvidas, a chave para se criar - e manter - vantagem competitiva tende a pertencer àquelas organizações que inovam continuamente." Não basta fornecer apenas aquilo que o mercado necessita, mesmo que seja melhor do que as organizações concorrentes num dado momento, a chave para a vantagem competitiva está na inovação descontinua, ou melhor, na destruição criativa, como diria Schumpeter, citado por Calazans (1992), que significa uma constante procura por algo novo que simultaneamente destrói velhas regras e estabelece novas.

\section{REFERÊNCIAS}

Anthony, Scott D.; Christensen, Clayton M. (2007). O Caminho para a disrupção. Subtítulo em: Harvard Business School: Implementando a inovação. Rio de janeiro: Elsevier, pg. 19- 28.

Barney, Jay B. (2007). Administração estratégica e vantagem competitiva. São Paulo: Pearson Prentice Hall.

Bardin, L. ( 1977). Análise de Conteúdo, Lisboa: Edição 70. 
Chiavenato, Idalberto. (2003). Introdução à Teoria Geral da Administração: uma visão abrangente da moderna administração das organizações. $7^{\text {a }}$ Ed. Rio de Janeiro: Elsevier.

Chandler, A. D. (1990). Scale and scope: the dynamics of industrial capitalism. Harvard University Press: Cambridge.

Corrêa, Henrique L. Corrêa, Carlos A. (2010). Administração da produção e operações: manufatura e serviços: uma abordagem estratégica. São Paulo: Atlas.

Calazans, Roberto Balau. (1992 ). A lógica de um discurso: o empresário schumpeteriano. Ensaios FEE, v. 13, n. 2, p. 640-667.

Drucker, Peter. (1987), Inovação e Gestão: uma nova concepção de estratégia de empresa. Lisboa: Editorial Presença.

Grisotto, Raquel; Rydlewsky, Carlos. (2015) Época Negócios: Como derrubar uma empresa. São Paulo: Editora Globo S.A, n. 96, fev. Mensal. pág 58 a 69.

Hisrich, Robert D; Peters, Michael P; Shepherd, Dean A. (2009). Empreendedorismo. Trad. Teresa Felix de Sousa. 7. Ed. Porto Alegre: Bookman.

Isaacson, Walter. (2011). Steve Jobs: a biografia. São Paulo: Companhia das Letras.

Kim, W,Chan; Mauborgne, R. (2005). A estratégia do Oceano Azul: como criar novos mercados e tornar a concorrência irrelevante. Rio de janeiro: Elsevier.

Luedemann, Marta da S. (2003).Transformações na indústria automobilística mundial: o caso do complexo automotivo no Brasil 1990 - 2002. Tese de Doutorado. Universidade de São Paulo, São Paulo, SP, Brasil.

Martín, Luis A.; López, José M. (2007). La Dirección Estratégica de la Empresa: teoria y aplicaciones. Pamplona: Editorial Aranzadi.

Oliveira, Djalma de Pinho R. (2012). Estratégia empresarial e vantagem competitiva: como estabelecer, implementar e avaliar. 8.ed. São Paulo: Atlas.

Silva, Edna Lúcia; Menezes, Estera M. (2001), Metodologia da pesquisa $e$ elaboração de dissertação.- 3 a ed.rev. atual- Florianópolis: Laboratório de Ensino a Distância da UFSC.

Tidd, Joe; Bessant, John; Pavitt, Keith.(2008). Gestão da Inovação. 3.ed. Porto Alegre: Bookman.

Whittington, Richard. (2002). O que é estratégia. São Paulo: Pioneira Thomson Learning. 
Walter, Cicero E.S. (2014). A prática da Gestão Empresarial: um estudo de caso da UDI - Laboflor Centro de Exames Médicos. Gestão e Desenvolvimento, $\mathrm{N}^{\mathrm{o}} 22$, p. 55-72.

Yin, Robert K. (2005). Estudo de Caso: Planejamento e Método. - 3 ed. Porto Alegre, RS. Editora Bookman. 